\title{
Implementasi Manajemen Kurikulum 2013 di SMP IT Az-Zhahiriah
}

\author{
Iqrimah Silvi Ulviana $^{1 *}$, Abubakar ${ }^{1}$, Khalid Ramdhani ${ }^{1}$
}

${ }^{1}$ Universitas Singaperbangsa Karawang, Indonesia

\begin{abstract}
Abstrak: Penelitian ini bertujuan untuk mengetahui implementasi Kurikulum 2013 di SMP IT AzZhahiriah dalam upaya meningkatkan mutu pendidikan Islam. Metode penelitian yang digunakan adalah metode deskriptif dengan pendekatan kualitatif. Teknik pengumpulan data menggunakan metode wawancara, observasi dan studi dokumentasi. Teknik analisis data dengan mereduksi data dan penyajian data dalam bentuk naratif. Penelitian ini menunjukkan bahwa 1) perencanaan kurikulum 2013 di SMP IT Az-Zhahiriah terbagi menjadi dua yaitu perencanaan kurikulum internal dan eksternal. Perencanaan internal meliputi a) penyusunan perangkat pembelajaran; b) pembuatan kalender akademik; c) menganalisa kebutuhan guru, mengintegrasikan kurikulum umum dan tahfiz, menyesuaikan dengan silabus yang ditetapkan oleh Dinas Pendidikan. Sedangkan perencanaan eksternal yaitu dengan mengundang pengawas untuk sosialisasi terkait perangkat pembelajaran; dan 2) evaluasi manajemen kurikulum dilakukan dengan a) evaluasi input yang meliputi alokasi waktu evaluasi mingguan, semester, dan tahunan; b) evaluasi proses yang meliputi pembahasan evaluasi dimana dalam pembahasan evaluasi yaitu yang berkaitan dengan permasalahan-permasalahan yang belum tuntas tentang perangkat pembelajaran dan penyebaran angket ke siswa; dan c) evaluasi output yang meliputi perbaikan kurikulum kedepannya.
\end{abstract}

Kata Kunci: manajemen, kurikulum 2013, mutu pendidikan

\begin{abstract}
This study aims to determine the implementation of the 2013 curriculum at SMP IT AzZhahiriah in an effort to improve the quality of Islamic education. The research method used is a descriptive method with a qualitative approach. Data collection techniques using interviews, observation and documentation study. Data analysis techniques by reducing data and presenting data in narrative form. This research shows that 1) curriculum planning 2013 at SMP IT Az-Zhahiriah is divided into two, namely internal and external curriculum planning. Internal planning includes a) preparation of learning tools; b) making academic calendars; c) analyze teacher needs, integrate the general curriculum and tahfiz, adjust to the syllabus set by the Education Office. Meanwhile, external planning is by inviting supervisors for socialization related to learning tools; and 2) curriculum management evaluation is carried out by a) input evaluation which includes the allocation of time for weekly, semester, and annual evaluations; b) process evaluation which includes discussion of evaluation wherein the evaluation discussion is related to unfinished problems regarding learning tools and distributing questionnaires to students; and c) output evaluation which includes future curriculum improvements.
\end{abstract}

Keywords: management, curriculum 2013, quality of education

\footnotetext{
* Corresponding Author: Mohamad Fahri (absolutefahri@gmail.com). Kementerian Agama Jakarta, Indonesia
} 


\section{Pendahuluan}

Pentingnya mutu dapat dilihat dari dua perspektif, yaitu manajemen operasional dan pemasaran. Dalam perspektif manajemen operasional, mutu produk berfungsi dalam meningkatkan daya saing suatu produk yang dapat memberikan kepuasan kepada pelanggan. Bagi lembaga pendidikan, mutu lulusan menjadi suatu hal yang sangat penting karena memungkinkan pelanggan memperoleh kepuasan. Kepuasan pelanggan memungkinkan mereka setia menggunakan lulusan lembaga pendidikan tersebut. Jika pelanggan dan pengguna semakin setia dalam menggunakan lulusn atau produk, suatu lembaga pendidikan akan menjadi komparatif dan kompetitif untuk eksis dan solid dalam berproduksi.

Sedangkan Penjaminan mutu pendidikan dasar dan menengah berperan pentinng untuk: a) kesatuan unsur yang terdiri atas organisasi, kebijakan, dan proses terpadu yang mengatur segala kegiatan untuk meningkatkan mutu secara sistematis, terencana dan berkelanjutan. b) memastikan pemenuhan standar pada satuan pendidikan secara sistemik, holistik, dan berkelanjutan, sehingga tumbuh dan berkembang budaya mutu pada satuan pendidikan secara mandiri. c) berfungsi sebagai pengendali penyelenggaraan pendidikan oleh satuan pendidikan untuk mewujudkan pendidikan yang bermutu.

Dalam sistem pendidikan nasional, di nyatakan bahwa kurikulum adalah seperangkat rencana dan pengaturan mengenai tujuan, isi, dan bahan pelajaran serta cara yang digunakan sebagai pedoman penyelenggaraan kegiatan pembelajaran untuk mencapai tujuan pendidikan tertentu. Pendidikan nasional menurut UU No. 20 tahun pasal 3 tentang undang-undang Sisdiknas (2007, 52) yang bertujuan untuk mengembangkan kemampuan, membentuk watak serta peradaban bangsa yang bermartabat dalam rangka mencerdaskan kehidupan bangsa, berkembangnya poptensi peserta didik agar menjadi manusia yang beriman dan bertaqwa kepada Allah Swt. berakhlak mulia, sehat, berilmu, cakup, kreatif, mandiri, dan menjadi warga negara yang demokrtis serta bertanggung jawab.

Menurut Djuwarijah (2008, 205-206) Manajemen kurikulum meliputi dan di pengaruhi oleh beberapa komponen pendidikan serta lingkungan eksternal dapat dilihat dari segi isi (materi), metode, tujuan, proses, guru peserta didik, lingkungan sosial, ekonomi, budaya, dan agama. Jadi, manajemen kurikulum adalah suatu komponen pendidikan yang saling mensuport serta menentukan keberhasilan implementasi program pendidikan disuatu lembaga pendidikan. Selain itu lembaga pendidikan juga sangan di anjurkan untuk melihat dan mengikuti perkembangan masyarakat yang dapat dilihat dari bebrapa aspek sehingga kebutuhan kurikulum sekolah sesuai dengan keinginan masyarakat maupun kebutuhan peserta didik (bakat, potensi, minat).

Dalam Islam Perencanaan merupakan salah satu aspek harus ditekankan sebagaimana Allah Swt berfirman dalam surah Al-Haysr ayat 18 sebagai berikut:

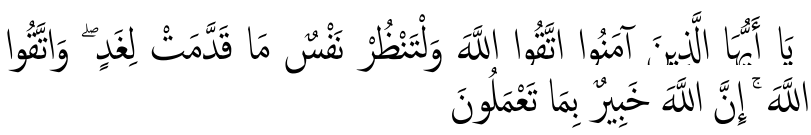

Artinya: Hai orang-orang yang beriman, bertakwalah kepada Allah dan hendaklah setiap diri memperhatikan apa yang telah diperbuatnya untuk hari esok (akhirat); dan bertakwalah kepada Allah, sesungguhnya Allah Maha Mengetahui apa yang kamu kerjakan. (Al-Haysr: 18)

Manajemen kurikulum merupakan salah satu komponen penting dalam sebuah lembaga pendidikan dimana manajemen kurikulum sangat 
berpengaruh terhadap mutu pendidikan. Pendidikan dikatakan berkualitas apabila telah berhasil menciptakan output yang hasilnya sesuai dengan tujuan yang telah di tetapkan.

Pengembangan kurikulum kurtilas (kurikulum 2013) di SMP IT Az-Zhahiriah mengacu pada standar nasional pendidikan (SNP) yang berdiri atas standar isi, standar proses pembelajaran, standar kompetensi lulusan, standar pengelolaan, standar pembiayaan dan standar penilaian kurikulum SMP IT Az-Zhahiriah di sesuaikan dengan kondisi sekolah yang merupakan sekolah Islam terpadu.

SMP IT Az-Zhahiriah di bangun bertujuan untuk memudahkan dan menghilangkan kekhawatiran masyarakat setempat agar anak mereka menemukan lembaga pendidikan yang tepat, juga dengan jarak yang terjangkau.

SMP IT Az-Zhahiriah melakukan pembelajaran secara menyeluruh yang memadukan unsur Al-Quran, unsur Islam dan intelektual peserta didik yang berfokus pada pembentukan akhlak dan kemampuannya dalam mengetahi ajaran-ajaran tentang Islam. Sehingga kurikulum yang ada di SMP IT Az-Zhahiriah ini hanya kutilas (kurikulum 2013).

Berdasarkan dari profil kelulusan, SMP IT Az-Zhahiriah telah mencetak lulusan-lulusan yang bermutu yang dapat di lihat dari segi nilai, dan prestasinya yang setara dimana beberapa lulusan SMP IT Az-Zhahiriah juga telah ada yang berhasil menghafal juz 30 dengan syarat lulusnya itu diwajibkan untuk anak santri yang pesantren juga bersekolah di SMP IT Az-Zhahiriah, SMP IT AzZhahiriah juga telah banyak meraih prestasiprestasi yang sangat membanggakan bagi sekolah maupun orang tua. Salah satu prestasi yang di dapat SMP IT Az-Zhahiriah yaitu permainan dram band, kegiatan lomba marawis, kegiatan pramuka dan masih banyak kegiatan lainnya.

\section{Metode Penelitian}

Adapun jenis penelitiannya adalah deskriptif kualitatif. Penelitian deskriptif kualitatif tidak dimaksudkan untuk menguji hipotesis, melainkan hanya menggabarkan suatu variabel, gejala, dan keadaan yang diteliti secara apa adanya. Metode deskriptif digunakan untuk melukiskan secara sistematis fakta atau karakteristik populasi tertentu, atau bidang tertentu, dalam hal ini bidang secara aktual dan cermat. Dalam penelitian kualitatif penulis mengunakan istrumen dengan cara wawancara, observasi dan dokumentasi. Dalam penelitian ini menggunakan jenis data kualitatif dari sumber primer dan sumber sekunder. Teknik yang digunakan dalam penelitian ini adalalah metode nonstatistik yaitu analisis data deskriptif data yang diperoleh dari penelitian tentang implementasi manajemen kurikulum 2013 untuk meningkatkan mutu pendidikan Islam. Analisis data dalam penelitian kualitatif dilakukan sejak sebelum memasuki lapangan, selama di lapangan dan setelah selesai di lapangan.

\section{Hasil Penelitian dan Pembahasan}

\section{Perencanaan Kurikulum 2013 dalam Meningkatkan Mutu Pendidikan di SMP IT Az- Zhahiriah}

Dalam penemuan penelitian tentang perencanaan kurikulum 2013 dalam meningkatkan mutu pendidikan di SMP IT Az-Zhahiriah terbagi menjadi dua yaitu perencanaan kurikulum internal dan eksternal. Pertama secara internal yaitu dengan mengadakan rapat koordinasi (pimpinan dan bawahan). Dalam rapat ini akan membahas hal-hal yang berkaitan dengan perencanaan kurikulum yaitu: a) penyusunan perangkat pembelajaran, b) 
pembuatan kalender akademik, c) menganalisa kebutuhan guru, mengintegrasikan kurikulum umum dan tahfiz, menyesuaikan dengan silabus yang ditetapkan oleh Diknas. Kedua secara eksternal yaitu dengan mengundang pengawas untuk sosialisasi terkait perangkat pembelajaran. Dalam hal ini bertujuan untuk menyesuaikan perangkat akademik dengan yang telah ditentukan oleh Diknas.

Menurut teori Omar Hamalik $(2011,171)$ berdasarkan hasil temuan di atas didukung oleh teori yang di kemukakan oleh Beane James yaitu perencanaan kurikulum sebagai suatu proses yang melibatkan berbagai unsur peserta dalam banyak tingkatan membuat keputusan tentang tujuan belajar, cara mencapai tujuan tersebut melalui situasi mengajarbelajar, serta penelaahan keefektifan dan kebermaknaan metode tersebut.

Faktor Penghambat dan Pendukung Perencanaan Kurikulum 2013 untuk Meningkatkan Mutu Pendidikan Islam di SMP IT Az-Zhahiriah

Dalam penemuan peneliti tentang faktor pendukung yang menjadi penghambat perencanaan kurikulum 2013 untuk meningkatkan mutu pendidikan islam di SMP IT Az-Zhahiriah yaitu meneliti tentang faktor apa saja yang menjadi penghambat sekolah untuk melakukan perencanaan kurikulum 2013 dan ada juga faktor pendukung dari perencanaan kurikulum 2013 tersebut yang sudah disepakati bersama.

Salah satu faktor penghambat yang penting untuk melihat berhasilnya implementasi kurikulum adalah guru. Karena guru memiliki peranan yang sangat penting, sebab menurut Silverius (dalam Kurinasih dan Sani, 2014, 13), "guru adalah tokoh sentral pendidikan dalam upaya menyiapkan kader bangsa masa depan, kunci sukses reformasi pendidikan". Perubahan kurikulum di Indonesia yang dilakukan oleh pemerintah adalah dengan tujuan untuk memperbaiki sistem pendidikan. Meskipun pada kenyataannya setiap kurikulum pastilah memiliki kekurangan dan perlu dievaluasi serta diperbaiki agar tujuan pendidikan tercapai dengan baik. Dengan diberlakukannya kurikulum 2013 sebagai kurikulum baru diharapakan peserta didik dapat menjadi individu yang lebih baik lagi dalam kegiatan akademik maupun nonakademik. Menurut Mulyasa $(2014,39)$, "kunci sukses dalam kurikulum 2013 antara lain berkaitan dengan kepemimpinan kepala sekolah, kreativitas guru, aktivitas peserta didik, sosialisasi, fasilitas dan sumber belajar, lingkungan yang kondusif akademik, dan partisipasi warga sekolah". Jadi jelas bahwa ada beberapa faktor penting dalam mengimplementasikan kurikulum 2013 yaitu, kepala sekolah, guru, peserta didik, sosialisasi, fasilitas dan sumber belajar, serta partisipasi warga sekolah.

\section{Evaluasi Kurikulum $2013 \quad$ Upaya Meningkatkan Mutu Pendidikan di SMP IT Az- Zhahiriah}

Hasil penelitian di SMA Al-Izzah IIBS Batu menunjukan bahwa terdapat beberapa implementasi kurikulum yang dilakukan oleh lembaga dalam proses menuju kearah yang lebih baik dari segi pembelajarannya maupu kelembagaanya. implementasi kurikulum tersebut diantaranya adalah: a) Evaluasi Input yang meliputi alokasi waktu evaluasi dimana dalam alokasi waktu ini dapat dialokasikan menjadi tiga yaitu evaluasi mingguan (senin dan sabtu), semester, dan tahunan; b) Evaluasi Proses yang meliputi pembahasan evaluasi dimana dalam pembahasan evaluasi yaitu yang berkaitan dengan permasalahanpermasalahan yang belum tuntas tentang perangkat pembelajaran (prota, promes, silabus, RPP) dan penyebaran angket ke santri; c) 
Evaluasi Output yang meliputi perbaikan kurikulum kedepannya.

Berdasarkan hasil temuan mengenai evaluasi input di atas didukung oleh teori menurut Oemar Hamalik $(2011,259)$ evaluasi input adalah evaluasi yang dapat merumuskan pemecahan masalah terkait dengan hambatan, kecakapan kerja (para guru), keampuhan, dan biaya ekonomi. Selain itu $S$. Nasution (2010, 95-96) juga menyatakan bahwa evaluasi input merupakan strategi implementasi kurikulum ditinjau dari segi efektifitas dan ekonomi. Jadi, dari evaluasi input kurikulum ini diharapkan menghasiklkan pemecahan masalah pada unsur-unsur internal akademik dan sekolah.

Evaluasi input yang meliputi alokasi waktu evaluasi. Terkait dengan alokasi waktu evaluasi SMP IT Az-Zhahiriah bisa dikatakan cukup baik dalam perbaikan kurikulum kedepannya karena selalu adanya pengevaluasian setiap minggu, semester, dan tahunan.

Evaluasi output yang meliputi perbaikan kurikulum kedepannya. Untuk menciptakan kurikulum yang lebih baik yaitu dengan terus-terus mengevaluasi perangkat pembelajaran, kinerja gurunya dan lain-lain.

Berdasarkan hasil temuan penelitian yang peneliti jabarkan di atas terkait dengan evaluasi input, pada dasarnya sejalan dengan teori yang dikemukan oleh Hamid Hasan (2009, 42-43) yang mengatakan ada beberapa tujuan dari kurikulum yaitu:

a. Menyediakan informasi mengenai pelaksanaan pengembangan dan pelaksanaan suatu kurikulum sebagai masukan bagi pengambilan keputusan.

b. Menentukan tingkat keberhasilan dan kegagalan suatu kurikulum serta faktor-faktor dan berkontribusi dalam suatu lingkungan. c. Mengembangkan berbagai alternatif pemecahan masalah yang dapat digunakan dalam upaya perbaikan kurikulum.

d. Memahami dan menjelaskan karakteristik suatu kurikulum dan pelaksanaan suatu kurikulum.

Jadi, evaluasi dilakukan setelah rencana dilaksanakan sebagai penyempurnaan atas kualitas dari pelaksanaan itu.

\section{Kesimpulan}

Penelitian ini menyimpulkan bahwa perencanaan kurikulum 2013 upaya meningkatkan mutu pendidikan islam terdiri dari perencanaan kurikulum yaitu a) mengadakan rapat (TIM INTI) yaitu kepala sekolah, waka kurikulum, waka kesiswaan, waka sarpras, koord. Cambridge dan guru serta mengundang pengawas sekolah yang di utus langsung dari provisni untuk mengadakan sosialisasi terkait pembuatan perangkat pembelajaran. Faktor pendukung dan penghambat implementasi manajemen kurikulum 2013 upaya meningkatkan mutu pendidikan Islam dapat di simpulkan bahwa banyak sekali yang menjadi penghambat perencanaan kurtilas di SMP IT AzZhahiriah juga ada beberapa faktor pendukunnya dalam melaksanakan kurtilas tersebut. Evaluasi kurikulum 2013 upaya meningkatkan mutu pendidikan Islam terdiri dari Evaluasi Input yang meliputi: a) alokasi waktu evaluasi, b) Evaluasi Proses yang meliputi: pembahasan evaluasi yang berkaitan denga perangkat pembelajaran, c) Evaluasi Output yang meliputi: perbaiki kurikulum kedepannya

\section{Daftar Pustaka}

Djuwarijah. 2008. Strategi Peningkatan Manajemen Kurikulum Dalam Pengembangan Mutu SDM Menuju Terwujudnya Lulusan Madrasah Aliyah 
Berwawasan Internasional. El-Tarbawi. Vol. 1. No. 2

Tim Redaksi Sinar Grafika. 2007. Undang-Undang Sisdiknas 2003 (Jakarta: Sinar Grafika) Undang-Undang Guru dan Dosen:UU RI No.14 Th. 2005 dan Undang-Undang SISDIKNAS (Sistem Pendidikan Nasional)UU RI No. 20 Th. 2003(Asa Mandiri, 2007)

Hamalik, Oemar. 2011. Dasar-dasar Pengembangan Kurikulum Bandung: Remaja Rosdakarya.

Padjrin, P. (2016). Pola Asuh Anak dalam Perspektif Pendidikan Islam. Jurnal Intelektualita: KeIslaman, Sosial Dan Sains, 5(1), $\quad 1 \quad-14$. https://doi.org/https://doi.org/10.19109/intele ktualita.v5i1.720

Zaini, H., Hadi, A., Sofvan, F. A., \& Hamzah, A. (2021). Covid-19 and Islamic Education in School: Searching for Alternative Learning Media. Webology, 18(1).

Kurinasih, Imas dan Berlin Sani. (2014). Implementasi Kurikulum 2013: Konsep dan Penerapan. Surabaya: Kata Pena.

Mulyasa. (2014). Pengembangan dan Implementasi Kurikulum 2013. Bandung: PT. Remaja Rosdakarya.

Nasution S. 2010. Kurikulum dan Pengajaran. Bumi Aksara

Hamid Hasan, S. 2009. Evaluasi Kurikulum (Bandung: Remaja Rosdakarya) 